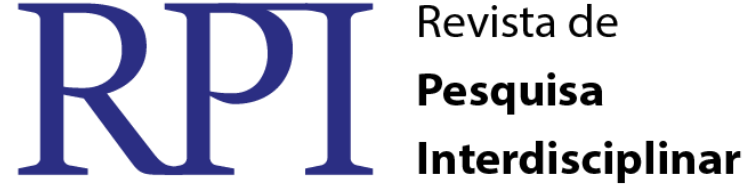

\section{RADIOATIVIDADE NO ENSINO MÉDIO: ANÁLISE DE LIVROS DIDÁTICOS DE QUÍMICA NO PNLD 2015}

\author{
Windson Timoteo de Sousa - UACEN/CFP/UFCG \\ Luciano Leal de Morais Sales - UACEN/CFP/UFCG
}

\section{RESUMO}

Este trabalho busca avaliar o conteúdo de Radioatividade nos livros didáticos escolhidos pelo PNLD 2015 utilizados nas escolas públicas de acordo com os critérios estipulados pelos Programas Curriculares Nacionais (PCN's). A pesquisa da bibliografia foi obtida através de uma detalhada busca na literatura especifica visando qualificar a descrição dos critérios necessários para que o livro cumpra todas as exigências para uma boa compreensão dos conceitos trabalhados em sala de aula sendo estes: imagens presentes no livro didático; linguagem e rigor científico; evolução histórica do conteúdo; contextualização do conteúdo; abordagem metodológica do conteúdo; relacionamento do conteúdo com o desenvolvimento tecnológico; aspectos inerentes aos exercícios e problemas que são disponibilizados. Após a análise dos resultados foi constatado que há uma grande inadequação desses livros em relação ao que se espera de um livro didático, mostrando que apenas duas das obras selecionadas pelo PNLD 2015 possuem certo grau de satisfação para trabalhar o tema Radioatividade estando em concordância com os padrões de qualidade de ensino estabelecidos pelo MEC, enquanto outra obra apresenta-se como totalmente ineficaz para o estudo do tema abordado, o que se demonstra como um erro o fato da escolha de uma obra como esta para compor o Programa Nacional do Livro Didático. Vale ressaltar que o livro ainda é a tecnologia mais utilizada em sala de aula, sendo assim, torna-se um elemento ímpar de pesquisa para campo de estudo dos alunos da área e instrumento de apoio ao trabalho do professor, portanto suas imperfeições comprometem diretamente no processo ensino e aprendizagem.

Palavras-chave: Análise. Radioatividade. PNLD.

\section{THE RADIOACTIVITY IN SECONDARY EDUCATION: CHEMISTRY TEXTBOOK ANALYSIS IN PNLD 2015}

\begin{abstract}
This study aspires to evaluate the content of Radioactivity in textbooks chosen by PNLD 2015 used in public schools according to the criteria established by the National Curriculum Programs (NCP's). The analysis of the results was obtain through a detailed description of the necessary criteria in order to the book fulfill all the requirements for a good comprehension of the concepts learned in the classroom, such as images present in the textbook; language and scientific rigor; historical evolution of content; contextualization of the content; methodological approach to content; relationship content with technological development; aspects of the exercises and problems that are available. After analyzing the results it was deduced that, in these books, there is a large inappropriateness regarding to what is expected from a textbook, showing that only two of the books selected by PNLD 2015 have a certain degree of satisfaction in relation to Radioactivity while
\end{abstract}


preserving itself honest in regard to the standards of education established by the MEC, while the other one is presented as totally ineffective to the study the topic addressed previously, which can be seen as a mistake due to the fact that the choice of such textbook to constitute the National Textbook Program. It is evident that the book is still the most used technology in the classroom, therefore, it becomes an important element and a considerable support tool for both students and teacher, then, its imperfections compromise directly the teaching-learning process.

Keywords: Analysis. Radioactivity. PNLD.

\section{INTRODUÇÃO}

As descobertas de Röntgen, Becquerel, Curie e Rutherford e o desenvolvimento posterior do modelo nuclear do átomo mostraram que a radioatividade é produzida pelo decaimento nuclear, ou seja, a decomposição parcial de um núcleo. A mudança de composição de um núcleo é chamada de reação nuclear. Os núcleos são formados por prótons e nêutrons que são coletivamente chamados de núcleons. Um núcleo específico com número de massa e número atômico determinados é chamado de nuclídeo. As reações nucleares diferem das reações químicas em alguns aspectos importantes. Primeiramente, isótopos diferentes de um mesmo elemento sofrem essencialmente as mesmas reações químicas, mas seus núcleos sofrem reações nucleares bem diferentes. Em segundo lugar, quando o as partículas $\alpha$ ou $\beta$ são emitidas pelo núcleo, forma-se um núcleo com número diferente de prótons que é chamado de núcleo-filho, e, portanto, núcleo de átomo diferente. Neste caso ocorre uma transmutação nuclear, isto é, a conversão de um elemento em outro (Atkins, 2012).

Por volta de 1934, o físico italiano Enrico Fermi notou que o bombardeamento do núcleo de certos átomos com velocidade moderada fazia com que o núcleo capturasse o nêutron. Isso levou Fermi a concluir que o bombardeamento do urânio $(Z=92)$ com nêutrons moderados deveria produzir elementos transurânicos $(Z>92)$, até então desconhecidos. Realizando experiências similares, o químico Otto Hahn e Fritz Stassmann, em 1938, detectaram a presença de bário $(\mathrm{Z}=56)$, após o bombardeamento do urânio com nêutrons moderados. A explicação para esse fato foi dada por uma cientista da equipe, a física austríaca Lise Meitner, e por seu sobrinho, o físico Otto R. Frisch: O núcleo do átomo de urânio é instável e, ao ser bombardeado com nêutrons moderados, rompe-se praticamente ao meio, 
originando dois núcleos de massa média e liberando 2 ou 3 nêutrons, além de mais energia. A esse fenômeno foi dado o nome de fissão nuclear (Xavier et al, 2007).

Nesse contexto, Medeiros e Lobato (2010) acreditam que o ensino de radiações pode ser apoiado em material didático que aborde o conteúdo de maneira contextualizada, mostrando avanços tecnológicos promovidos pela utilização das radiações e as formas de interação com a matéria, descrevendo-as e explicando-as, diferentemente de como o conteúdo é abordado em alguns livros didáticos de Ensino Médio.

Gouvêa e Machado (2005) acreditam que a contextualização não se resume a exemplificar um conteúdo, mas é necessário propor situações problemáticas reais e buscar o conhecimento necessário para entendê-las e solucioná-las. Para Silva et al (2009), a contextualização inter-relaciona conhecimentos diferentes contribuindo para a estruturação de novos significados. E esses significados incorporam valores, pois destacam o cotidiano, favorecendo a formação de cidadãos com capacidade de discutir questões ambientais, sociais, econômicas e tecnológicas. Dessa forma os PCNEM (Brasil, 2002) afirmam que em termos gerais, a contextualização no ensino de ciências abarca competências de inserção da ciência e de suas tecnologias em um processo histórico, social e cultural e o reconhecimento e discussão de aspectos práticos e éticos da ciência no mundo contemporâneo.

As relações entre os livros didáticos em Química e as produções curriculares nas escolas são temáticas constantes em diversas análises que se referem a aspectos tão diversificados como a produção, a comercialização, a inserção do conhecimento na evolução histórica, a qualidade gráfica e a adequação dos conteúdos (Loguércio et al, 2001). Trabalhos evidenciam alguns aspectos fundamentais da construção do conhecimento químico e a própria noção de epistemologia da ciência estes livros didáticos podem produzir. Estudos justapõem as questões de conhecimento ao cuidado com o visual e com a diagramação dos livros como facilitadores ou não da compreensão dos conteúdos. Em outras perspectivas de análise, são realizadas investigações através de questões sociais e políticas (Apple, 1995). Como se pode perceber, existem inúmeras análises, nas mais diversas perspectivas teóricas e preocupadas com diferentes aspectos específicos dos livros didáticos. A partir dela se têm condições de analisar os materiais didáticos agregando novos critérios àqueles que já vinham sendo adotados (LOGUÉRCIO et al, 2001).

Portanto, este trabalho visa caracterizar os livros didáticos contidos no PNLD 2015 com intuito de verificar se os mesmos se encaixam nos critérios estabelecidos pelo MEC. 


\section{Metodologia}

O método de pesquisa utilizado neste trabalho foi uma pesquisa exploratória, onde foi analisada uma vasta bibliografia acerca do tema, com o objetivo de investigar se esses livros realmente seguem os critérios exigidos e qual sua importância como agente facilitador no processo de ensino-aprendizagem do conhecimento da Radioatividade. Dessa forma, foram analisados 4 livros de Química do Ensino Médio que contemplam o conteúdo de Radioatividade propostos pelo PNLD 2015.

As obras serão analisadas seguindo os seguintes critérios estabelecidos pelo MEC (Brasil, 1994): imagens presentes no livro didático; linguagem e rigor científico; evolução histórica do conteúdo; contextualização do conteúdo; abordagem metodológica do conteúdo; relacionamento do conteúdo com o desenvolvimento tecnológico; aspectos inerentes aos exercícios e problemas que são disponibilizados.

\section{Resultados e Discussões}

A partir das análises dos livros didáticos foi possível caracterizar através do Quadro 2:

Como se pode observar no Quadro 2 de análise dos livros didáticos, ao se deparar com o primeiro critério de análise, apenas o livro QUÍMICA CIDADÃ trouxe 58 imagens catalogadas onde trazem suporte para complementar o aprendizado textual, não comprometendo o entendimento pelo alto numero de imagens. Outro caso, foi o Ser protagonista que trouxe 20 imagens, que exprimem bem o assunto ao aluno e o Fonseca que trouxe 14 imagens com ótima qualidade, porém de pouco valor didático para a compreensão dos conceitos, o livro QUÍMICA (MORTINER; MACHADO) foi o livro menos ilustrado, isso pode dificultar o entendimento do alunado. As coleções analisadas apresentam uma satisfatória quantidade de imagens que podem trazer ao aluno uma noção mais detalhada de como, onde, e quais aplicações podem ser dadas a Radioatividade.

Em contrapartida, ao verificar o segundo critério de análise, vê-se a satisfação pelo fato de todos os livros apresentaram uma linguagem bem compatível com o nível escolar do público alvo, porém sempre mantendo o rigor e cientificidade que a Química exige, dessa RPIRevista de Pesquisa Interdisciplinar, Cajazeiras, v. 1, Ed. Especial, 73 - 79, set/dez. de 2016. 
forma fazendo com que o conteúdo seja mais facilmente compreendido pelos alunos e estimulando a busca pelo conhecimento a partir do momento em que transporta essa linguagem científica para uma linguagem cotidiana.

Ao analisar os dados mostrados no Quadro 2, a evolução histórica da Radioatividade, deve partir desde os conceitos iniciais dos Raios X de Röntgen, as descobertas dos elementos químicos radioativos de Pierre e Marie Curie e a emissão dos diferentes tipos de radiação. Neste contexto vemos a necessidade de um ensino que não busque apenas a questão de transmissão de conteúdos e fórmulas, mas sim um ensino que busque compreender a história da Química, para que se compreenda que a ciência não surge do nada, mas é fruto de uma construção histórica, política, econômica e social que se dá através dos tempos. Assim, analisando a evolução histórica contida nesses livros mostra que três deles trazem um desenvolvimento histórico favorável a construção do conhecimento do conteúdo, sendo o QUÍMICA CIDADÃ mais completo em relação à evolução histórica anteriormente citada. A coleção QUÍMICA dos autores Mortiner e Machado não apresenta essa evolução histórica, tampouco uma definição de conceitos para ser trabalhado o conteúdo, fragilizando o processo de aprendizagem dos discentes.

A contextualização sempre foi um problema para a compreensão de conteúdos complexos como a Radioatividade. Nas quatro obras analisadas, apenas a obra QUÍMICA da autora Fonseca não contempla essa relação entre os conceitos e a vida cotidiana dos discentes, sendo, portanto muito deficiente nesta questão. As demais obras buscam ao máximo trazer aqueles conceitos estudados para serem vivenciados pelos alunos de uma forma a produzir uma aprendizagem significativa. Ao considerar a abordagem metodológica de apresentação dos conteúdos, nota-se que busca elevar a capacidade de pensar do aluno, fazendo com que este, não se detenha apenas a estudar o assunto abordado, mas veja também a relação do mesmo com os demais, podendo assim, verificar que o livro QUÍMICA da autora Fonseca e o livro QUÍMICA CIDADÃ analisados trazem uma sequência de conceitos que facilitam a compreensão do conteúdo, a coleção SER PROTAGONISTA possui uma pequena deficiência nessa ordem sendo relativamente pontual na organização de seus conceitos, o que pode dificultar na assimilação do mesmo. Enquanto que a coleção QUÍMICA dos autores Mortiner e Machado não possui nenhuma organização de conceitos e ideias prejudicando a aprendizagem.

O conteúdo de Radioatividade abrange várias áreas da tecnologia, pesquisa e aplicações tais como Física, Química, Medicina, entre outras. Nesse caso o Quadro 2 traz o RPIRevista de Pesquisa Interdisciplinar, Cajazeiras, v. 1, Ed. Especial, 73 - 79, set/dez. de 2016. 
relacionamento do assunto com o avanço da tecnologia. De acordo com os dados, três obras se mostraram intimamente conectadas com o uso da tecnologia associada ao estudo das emissões nucleares, apresentando o papel da ciência sobre a sociedade, as implicações que isso pode trazer do ponto de vista ambiental dando grande enfoque ao que é produzido cientificamente e ao que ainda estar para ser produzido. Novamente a obra pelos autores Mortiner e Machado não trazem essa relação com o desenvolvimento tecnológico do conteúdo Radioatividade.

Ao serem contemplados os exercícios apresentados em cada livro didático assim como afirma Otesbelgue (2013), o qual prediz que os exercícios têm papel fundamental na formação do aluno, pois pode forçar o mesmo a contextualizar mais, levando os discentes a pesquisar sobre o assunto estudado. Assim, considera-se que as obras QUÍMICA da autora Fonseca e SER PROTAGONISTA trazem questões adequadas às necessidades dos alunos, questões estas de caráter contextualizado e interdisciplinar que levam o aluno a questionar, interpretar, avaliar e problematizar até chegar a resposta esperada. Na obra Química Cidadã, apenas uma pequena quantidade dos exercícios atende ao que é pedido, em sua maioria, eles são dados de uma forma bem direta, sem que haja uma associação com o cotidiano. A obra de QUÍMICA de Mortiner e Machado não traz exercícios referentes ao conteúdo de Radioatividade.

\section{Considerações Finais}

Conclui-se que dos 4 livros escolhidos para serem usados no PNLD 2015, quando analisados quanto aos critérios necessários para uma boa formação, As coleções SER PROTAGONISTA e QUÍMICA CIDADÃ se destacam em relação as demais pelo fato de encaixaram em mais critérios exigidos pelo MEC, sendo portanto, obras mais completas para trabalhar o conteúdo de Radioatividade.

No entanto, em cada uma das obras foi constatada falha em pelo menos um dos critérios analisados podendo prejudicar o desenvolvimento e interesse do aluno no conteúdo de Radioatividade.

\section{REFERÊNCIAS}

RPIRevista de Pesquisa Interdisciplinar, Cajazeiras, v. 1, Ed. Especial, 73 - 79, set/dez. de 2016. 
APPLE, Michael W. Trabalho Docente e Textos: Economia Política das Relações de Classe e Gênero em Educação; Artes Médicas, Porto Alegre, 1995.

ATKINS, Peter; JONEs, Loretta. Princípios de Química: questionando a vida moderna e o meio ambiente. 5 ed. Porto Alegre: Bookman, 2012.

BRASIL. Ministério da Educação (MEC), Secretaria de Educação Média e Tecnológica (Semtec). Parâmetros Curriculares Nacionais Para O Ensino Médio. Ciências da Natureza, Matemática e suas tecnologias. Brasília: MEC/Semtec, 2007. Ministério da Educação (MEC), Secretaria de Educação Média e Tecnológica (Semtec). Matriz de referência Enem - Ciências da Natureza, Matemática e suas tecnologias. Brasília: MEC/Semtec, 2012.

Ministério da Educação (MEC), Secretaria de Educação Média e Tecnológica

(Semtec). PCN + Ensino Médio: orientações educacionais complementares aos Parâmetros Curriculares Nacionais - Ciências da Natureza, Matemática e suas Tecnologias. Brasília: MEC/Semtec, 2002.

Guia de livros didáticos: PNLD 2015 : química : ensino médio. - Brasília : Ministério da Educação, Secretaria de Educação Básica, 2014.

GOUVEA, L. R. \& MACHADO, A. H. Trilhando caminhos para compreender a contextualização no ensino de Química. 2005. Monografia (Graduação em Química Licenciatura) - Faculdade de Educação

LOGUERCIO, R; SAMRSLA, V. E. E.; Del Pino, J. C. Livros textos de Química: análise na realidade dos docentes. Tecno-lóg. Santa Cruz do Sul, vol. 2, n 2, p. 53-64. Jul/Dez, 1998. MARTINS, Isabel; GOUVÊA, Guaracira. Analisando aspectos da leitura de imagens em livros didáticos de ciências por estudantes do ensino fundamental no Brasil. Enseñanza de las ciencias, n. Extra, p. 0001-3, 2005

MEDEIROS, Miguel A.; LOBATO, Anderson C. Contextualizando a abordagem de radiações no ensino de química. Ensaio Pesquisa em Educação em Ciências, v. 12, n. 3, p. 65, 2011 